\title{
Laboratory Flow Experiments for Visualizing Carbon Dioxide-Induced, Density-Driven Brine Convection
}

\author{
Timothy J. Kneafsey • Karsten Pruess
}

Received: 6 December 2008 / Accepted: 22 September 2009 / Published online: 17 October 2009

(C) The Author(s) 2009. This article is published with open access at Springerlink.com

\begin{abstract}
Injection of carbon dioxide $\left(\mathrm{CO}_{2}\right)$ into saline aquifers confined by lowpermeability cap rock will result in a layer of $\mathrm{CO}_{2}$ overlying the brine. Dissolution of $\mathrm{CO}_{2}$ into the brine increases the brine density, resulting in an unstable situation in which more-dense brine overlies less-dense brine. This gravitational instability could give rise to density-driven convection of the fluid, which is a favorable process of practical interest for $\mathrm{CO}_{2}$ storage security because it accelerates the transfer of buoyant $\mathrm{CO}_{2}$ into the aqueous phase, where it is no longer subject to an upward buoyant drive. Laboratory flow visualization tests in transparent Hele-Shaw cells have been performed to elucidate the processes and rates of this $\mathrm{CO}_{2}$ solute-driven convection (CSC). Upon introduction of $\mathrm{CO}_{2}$ into the system, a layer of $\mathrm{CO}_{2}$-laden brine forms at the $\mathrm{CO}_{2}$-water interface. Subsequently, small convective fingers form, which coalesce, broaden, and penetrate into the test cell. Images and time-series data of finger lengths and wavelengths are presented. Observed $\mathrm{CO}_{2}$ uptake of the convection system indicates that the $\mathrm{CO}_{2}$ dissolution rate is approximately constant for each test and is far greater than expected for a diffusion-only scenario. Numerical simulations of our system show good agreement with the experiments for onset time of convection and advancement of convective fingers. There are differences as well, the most prominent being the absence of cell-scale convection in the numerical simulations. This cell-scale convection observed in the experiments may be an artifact of a small temperature gradient induced by the cell illumination.
\end{abstract}

Keywords Carbon sequestration · Density-driven convection · Induction time

\section{Introduction}

Carbon dioxide $\left(\mathrm{CO}_{2}\right)$ injection into deep saline aquifers is a method being considered for sequestration of $\mathrm{CO}_{2}$. In such a scenario, the $\mathrm{CO}_{2}$ would be injected into a permeable, porous zone beneath a low-permeability cap rock, intending that the $\mathrm{CO}_{2}$ would remain in the aquifer

T. J. Kneafsey $(\varangle) \cdot$ K. Pruess

Lawrence Berkeley National Laboratory, Berkeley, CA, USA

e-mail: TJKneafsey@lbl.gov 
for an extended period of time. At the temperature and pressure conditions of the deep brine formations, $\mathrm{CO}_{2}$ will be in a supercritical state, and will have lower density than the native aqueous phase. Because of this lower density, the injected $\mathrm{CO}_{2}$ will tend to rise to the top of the permeable interval and spread out beneath the cap rock.

$\mathrm{CO}_{2}$ injected into brine aquifers can be stored in four different modes: (1) as a (mobile) separate supercritical phase, for simplicity here referred to as "free gas"; (2) as trapped gas; (3) dissolved in the aqueous phase; and (4) as solid minerals (IPCC 2005). Initially, most of the injected $\mathrm{CO}_{2}$ will be present as free gas, but over time the other modes of storage become more important (IPCC 2005; Audigane et al. 2007). Residence times and relative amounts of $\mathrm{CO}_{2}$ in each of these modes are of great interest because storage security and storage permanence increase as $\mathrm{CO}_{2}$ is trapped, then dissolved, and then eventually chemically bound to solid phases.

At some distance from the injection well where the $\mathrm{CO}_{2}$ has spread out under the cap rock, there will likely be a nearly horizontal interface between a free $\mathrm{CO}_{2}$ phase above and the aqueous phase below. Geometric details of the interface will be affected by the properties of the porous media; for simplicity, we will consider the interface to be flat. At the interface, $\mathrm{CO}_{2}$ will dissolve into the aqueous phase. If the aqueous phase was immobile, the rate of $\mathrm{CO}_{2}$ dissolution would be limited by the rate at which $\mathrm{CO}_{2}$ can be removed from the interface by molecular diffusion. This is a slow process, and the rate of $\mathrm{CO}_{2}$ dissolution will decrease with time.

$\mathrm{CO}_{2}$ dissolution causes the density of the aqueous phase to increase on the order of 0.1 to $1 \%$, depending on $\mathrm{CO}_{2}$ pressure, temperature, and salinity (Garcia 2001). This density increase induces a gravitational instability because denser $\mathrm{CO}_{2}$-rich aqueous fluid overlies less-dense fluid. The instability can trigger convection of fluid at a variety of scales, which could greatly increase the rate at which dissolved $\mathrm{CO}_{2}$ is removed from the interface with the overlying free $\mathrm{CO}_{2}$, thereby accelerating $\mathrm{CO}_{2}$ dissolution. Some researchers have referred to this as density-driven convection (DDC), however, we refer to the convection induced by this $\mathrm{CO}_{2}$ dissolution into the brine as $\mathrm{CO}_{2}$-solute-driven convection (CSC) to avoid confusion with double-diffusive convection (also called DDC). $\mathrm{CO}_{2}$ dissolution-induced CSC has been studied by many investigators because of its relevance for security and permanence of $\mathrm{CO}_{2}$ storage. The earliest published study on $\mathrm{CO}_{2}$ dissolution-induced density increase and its importance for $\mathrm{CO}_{2}$ storage was by Weir et al. $(1995,1996)$. Lindeberg and Wessel-Berg (1997) evaluated the conditions under which vertical convective flow will occur in a medium subjected to both a thermal gradient and the presence of a $\mathrm{CO}_{2}$ dissolution-induced dense layer. Lindeberg and Bergmo (2003) examined CSC and multiscale numerical simulation problems related to the Sleipner Vest $\mathrm{CO}_{2}$ storage project in the Norwegian Sector of the North Sea. Studies have also been performed investigating stability analysis for the onset time for convection, the preferred wavelength for the growth of convective fingers, and growth rates (e.g., Ennis-King and Paterson 2003a,b; Ennis-King et al. 2005; Hesse et al. 2006; Riaz et al. 2006; Xu et al. 2006).

The references cited above also present numerical simulations to complement and partially confirm analytical stability theory. Using high-resolution simulations for extended time periods, Hesse et al. (2006) found that the total $\mathrm{CO}_{2}$ dissolution rate is constant during the convection-dominated period, excluding random fluctuations caused by the unstable nature of the underlying processes. Recently, Ennis-King et al. (2008) compared CSC for homogeneous media with simulations for heterogeneous media featuring a random distribution of shale bodies in a homogeneous sand background. Laboratory studies have confirmed qualitative and quantitative aspects of CSC (Yang and Gu 2006; Farajzadeh et al. 2007).

CSC has similarities to convection caused by a temperature gradient. An extensive literature on this subject (e.g., Garg and Kassoy 1981) has aided in understanding CSC. An 
important difference between the $\mathrm{CO}_{2}$ case and thermal convection studies is that a geothermal temperature gradient exists over the entire vertical range of the flow system, whereas the vertical range of the concentration gradient in the $\mathrm{CO}_{2}$ case is near zero initially and continuously grows with time. There is no significant pre-existing gradient of dissolved aqueous $\mathrm{CO}_{2}$, and the system is unconditionally unstable with respect to buoyant convection.

The Rayleigh number $(R a)$ provides an indication of whether CSC will occur under the conditions of interest. $R a$ compares the rate of fluid convection (from a density increase for example) with the rate of diffusive transport. If the rate of convection greatly exceeds the system's ability to diffusively distribute the density increase, convection will occur. Theoretical studies have shown that if $R a>4 \pi^{2}$, CSC is expected. For CSC, the Rayleigh number is calculated as

$$
R a=\frac{k g h \gamma \Delta C \rho_{o}}{\mu D}
$$

where $k$ is permeability, $g$ is acceleration of gravity (here $g \sin \theta$, because we can incline our systems), $h$ is height of the fluid column, $\gamma$ is the partial derivative of density with respect to concentration, $\Delta \mathrm{C}$ is the increase of $\mathrm{CO}_{2}$ concentration in the water at the top boundary, $\mu$ is the viscosity of water, and $D$ is the diffusivity of $\mathrm{CO}_{2}$ in water (Lindeberg and Wessel-Berg 1997). The concentration gradient in the transient $\mathrm{CO}_{2}$ system will change over time as $\mathrm{CO}_{2}$ dissolves and diffuses; the length over which there is a gradient is almost zero initially (nearly infinite gradient), and without convection would grow with time proportional to $(D \mathrm{t})^{1 / 2}$. For this reason, in this article, we use a nominal $R a\left(R a_{n}\right)$ based on the height of the water column to provide a basis to compare tests.

An example of results from numerical simulations of CSC on the meter-scale is presented in Fig. 1 from Pruess and Zhang (2008). The dissolved $\mathrm{CO}_{2}$ concentrations throughout the region are plotted for six sequential times. The first frame in Fig. 1 shows the induction phase with the formation of many small convective fingers with wavelengths comparable to layer thickness (Ennis-King et al. 2005). Following that, the convective fingers advance downward and become broader, with some fingers coalescing.

Numerical studies have shown that CSC can occur and will enhance $\mathrm{CO}_{2}$ dissolution in brine aquifers if the conditions are favorable. Our goal here is to provide visual evidence of CSC on a time and space scale easily accessible in the laboratory. Such evidence aids in conceptual understanding of the process, provides data for model comparison, and provides tangible evidence of CSC for non-scientists who will ultimately be among the stakeholders if large-scale carbon sequestration is adopted.

In this article, we present the results of a series of CSC laboratory tests performed in transparent Hele-Shaw cells containing water overlain by gas. In the Hele-Shaw cells, fluid flows in the narrow gap between two parallel plates in a manner that is mathematically analogous (Darcy's law) to flow in porous media. Our experiments provide visual observations of CSC that closely resemble numerical simulation results. In these visualization experiments, we have observed system behavior during the induction phase, the formation of small convective fingers, and the development of cell-scale convection in our test cells. Quantitative tests to determine $\mathrm{CO}_{2}$ dissolution rates at near-reservoir pressure and temperature conditions are also being performed and will be described elsewhere.

\section{Method}

Transparent Hele-Shaw cells were made from smooth flat glass and sandblasted obscure (shower-door) glass. Two approximately page-size (dimensions for each cell are shown 

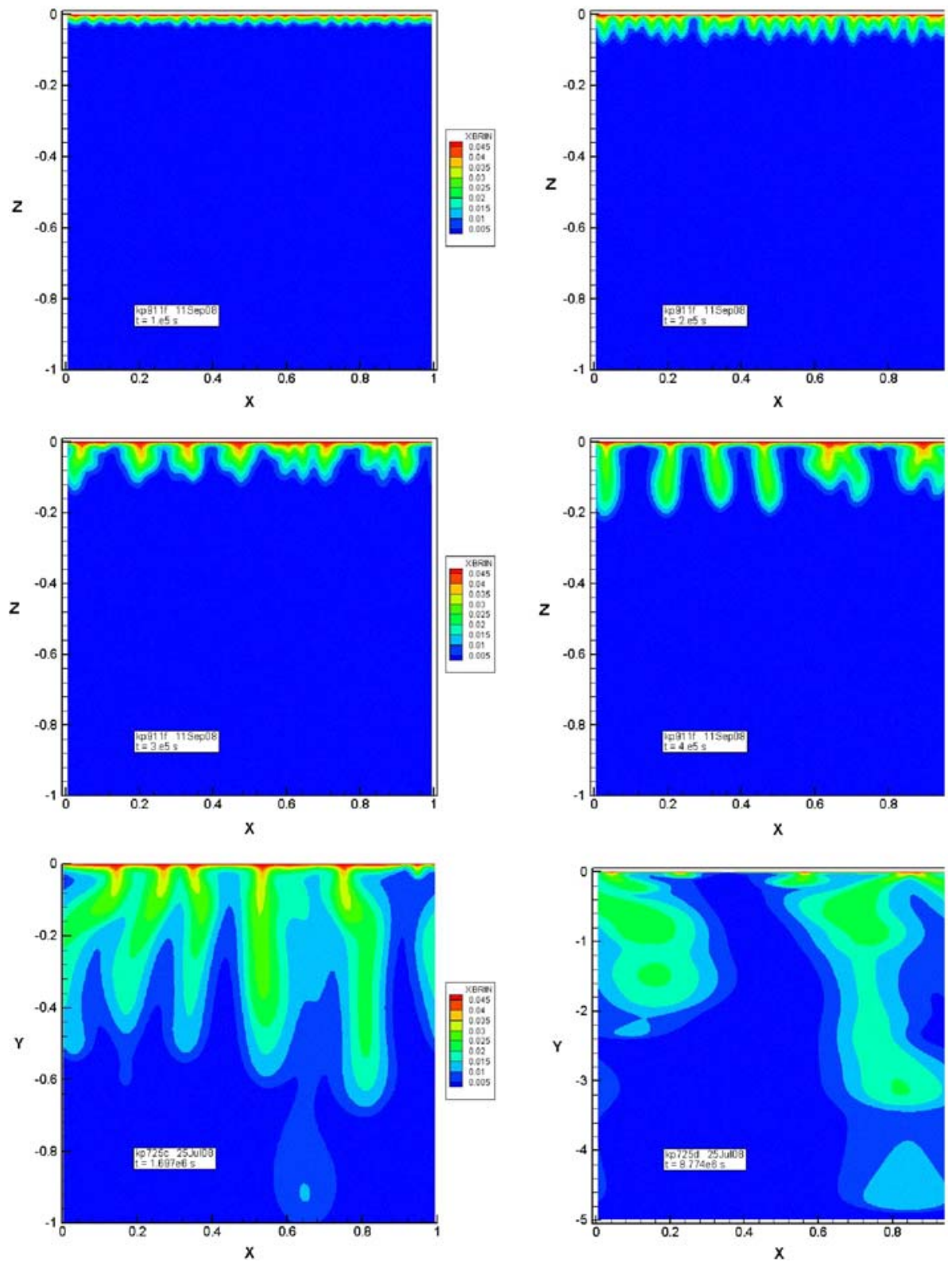

Fig. 1 Numerical simulation results showing dissolved $\mathrm{CO}_{2}$ concentrations at different times for a meter-scale 2-dimensional system. Note the change in vertical scale in the last frame

below) glass plates were separated by graphite shims (Pentel ${ }^{\mathrm{TM}}$ ) having known dimensions and sealed on the bottom and sides, leaving the top open (Fig. 2). Pure water in equilibrium with atmospheric air $\left(380 \mathrm{ppm}\right.$ of $\left.\mathrm{CO}_{2}\right)$ will have a $\mathrm{pH}$ near 5.6, and pure water in equilibrium with $\mathrm{CO}_{2}$ at one atmosphere will have a $\mathrm{pH}$ of about 3.9. As a means of visualizing different concentrations of dissolved $\mathrm{CO}_{2}$, we used bromocresol green, a $\mathrm{pH}$ indicator that changes from blue at $\mathrm{pH}$ values above 5.4 to yellow at $\mathrm{pH}$ values below 3.8. The bromocresol green 


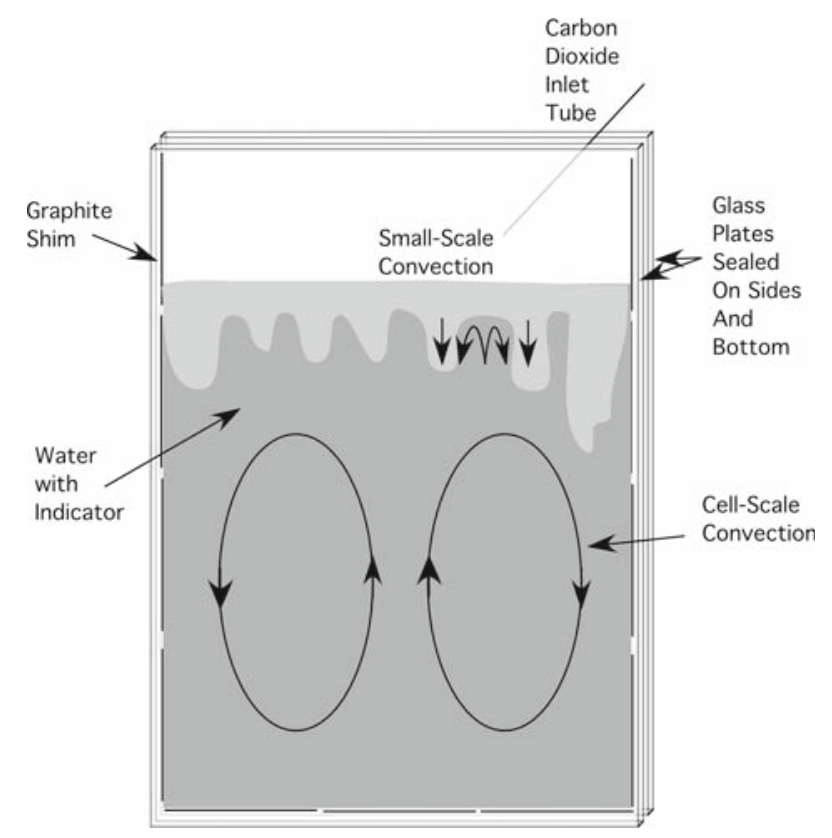

Fig. 2 Cell setup

$(0.1 \% \mathrm{w} / \mathrm{w})$ was diluted 1:30 with double-distilled, deionized, deaired water and introduced into the cell using a long, thin tube. $\mathrm{CO}_{2}$ was introduced using a narrow steel tube inserted between the glass plates at a rate of several tens of milliliters per minute (enough to produce a steady stream of small bubbles when the tube tip was submerged in a beaker of water). $\mathrm{CO}_{2}(\mathrm{MW} \sim 44 \mathrm{~g} / \mathrm{mol})$ is denser than air $(\mathrm{MW} \sim 29 \mathrm{~g} / \mathrm{mol})$ and thus will sink to the bottom of the air space in the Hele-Shaw cell, displacing air from the cell through the open top. The $\mathrm{CO}_{2}$ will establish equilibrium-dissolved concentrations at the top of the water-filled region, and dissolved $\mathrm{CO}_{2}$ will migrate into the interior of the water body initially by molecular diffusion, and at later times by convection as well.

The Hele-Shaw cell was illuminated from behind using a light table, and a digital camera (Canon Powershot S1 IS, or Olympus 8080CW) was used to image the experiments at specific intervals. Although $\mathrm{pH}$ changes in the system from $\mathrm{CO}_{2}$ dissolution were visible to the naked eye, direct imaging was difficult because light from the light table had to pass through only a very thin layer of the dilute bromocresol green solution. Thus, additional image processing was performed, including subtraction of the initial condition to enhance differences from that condition, and noise reduction.

Image processing was performed using ImageJ (Rasband 2008) and Graphic Converter (Lemke Software). The image processing consisted of reducing the spatial resolution (Olympus images only) using Graphic Converter to produce workable file sizes and change image orientation. Image sequences were imported into ImageJ, and a separate file containing the initial $\left(\right.$ no $\left.\mathrm{CO}_{2}\right)$ condition was also imported. The initial condition was subtracted from each image resulting in a difference images in RGB format. The RGB images were separated into images containing their individual red, green, and blue components. The red and green components were added together into an 8-bit file, and the blue component (containing mostly noise) was discarded. The gray-scale lookup table was inverted changing dark to light. This process results in regions with lower $\mathrm{pH}$ and larger aqueous $\mathrm{CO}_{2}$ concentrations appearing 


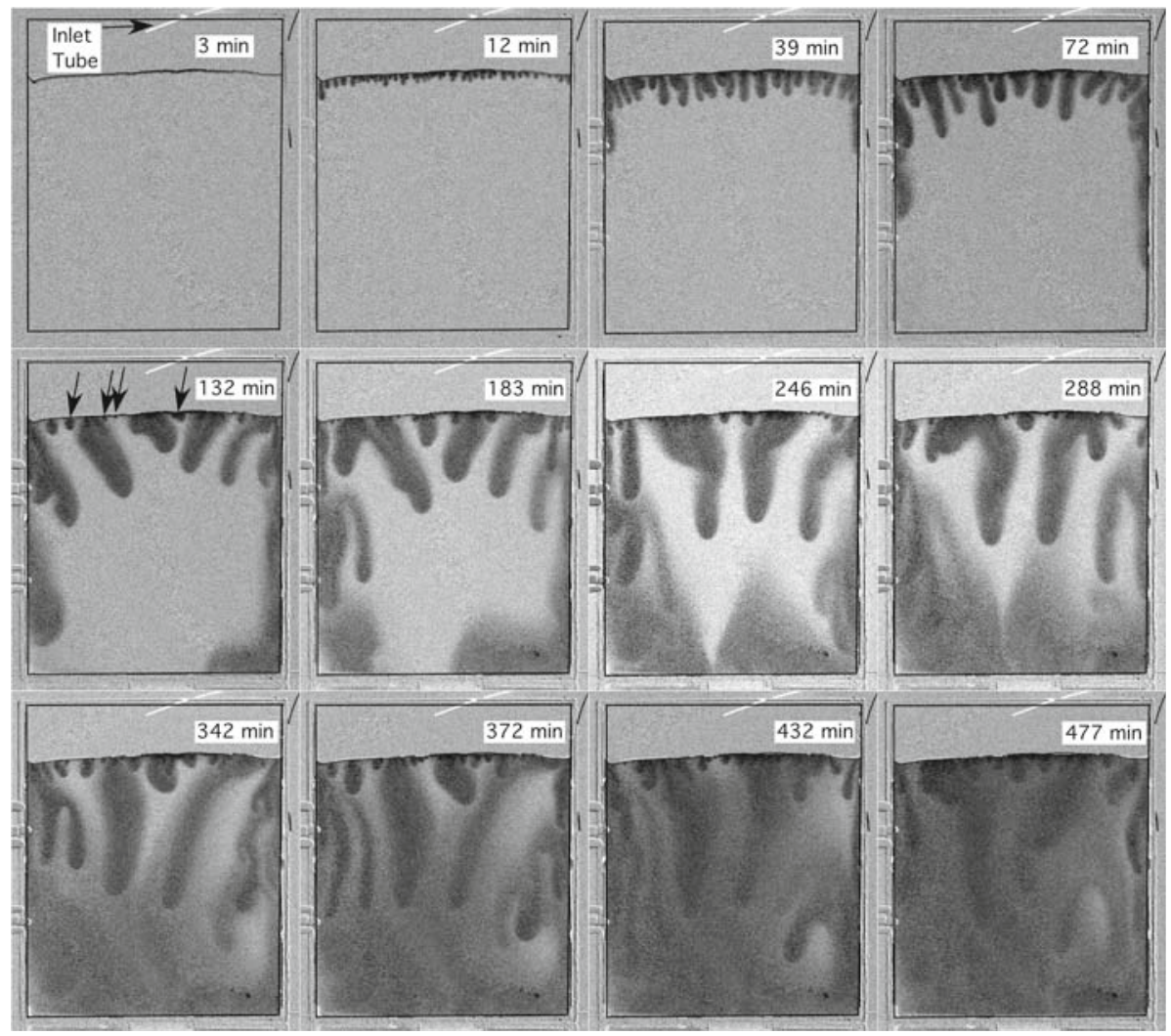

Fig. 3 Base Case. $0.7 \mathrm{~mm}$ aperture, flat glass, vertical orientation, $\mathrm{CO}_{2}$ introduced at gentle slope a distance from the interface. Arrows in Frame 5 (132 min) identify some of the new fingers forming

darker (see Fig. 3 ). For presentation in the figures here, the levels were adjusted by hand to provide the best viewable images. Additional image processing where needed is described below.

Four tests will be discussed in this article. The tests have been performed under a variety of conditions, including different apertures (affecting permeability, thus $R a$ ), relative amounts of heterogeneity in the flow path, methods of introduction of the $\mathrm{CO}_{2}$ (affecting shear at the water/gas interface), and orientation of the test cell with respect to the vertical (in effect varying the strength of gravity). CSC develops from instabilities, and the instabilities may be influenced by these conditions.

\section{Results}

3.1 Test A: Base Case-Vertically Oriented Flat Glass Plates, $0.7 \mathrm{~mm}$ Aperture, $R a_{\mathrm{n}}=1.2 \times 10^{5}$

The test cell in our Base Case was composed of two flat smooth pieces of glass $(25.4 \mathrm{~cm} \times$ $30.5 \mathrm{~cm}$ ) separated by $0.7 \mathrm{~mm}$ graphite spacers. $\mathrm{CO}_{2}$ was introduced near the center of the cell through a narrow steel tube at a relatively large distance from the gas/water interface, so that gas flow would impose a minimal shear stress on that interface. Images were collected every minute for $720 \mathrm{~min}$. The inlet tube is identified in Fig. 3. 


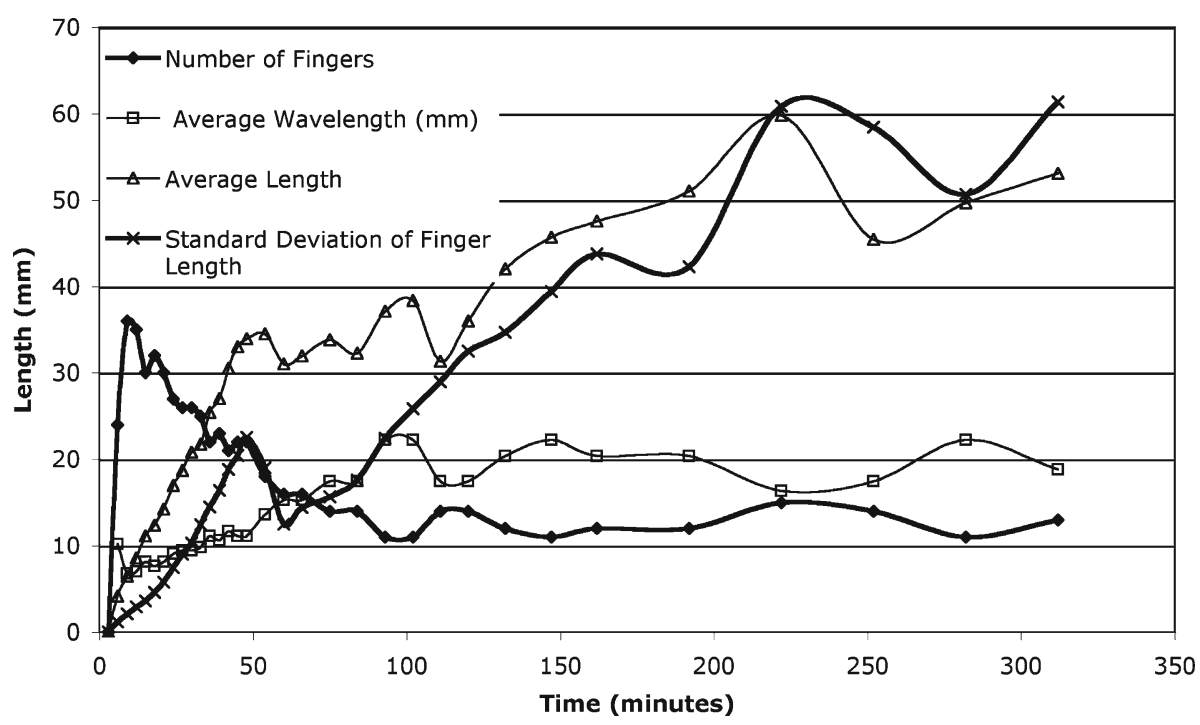

Fig. 4 Number of fingers, wavelength, and finger length statistics for the Base Case

Figure 3 shows a selection of sequential images of $\mathrm{CO}_{2}$ convective finger formation over time. In this and in subsequent figures, the image processing (discussed above) resulted in the lower $\mathrm{pH}$ fluid having the larger dissolved $\mathrm{CO}_{2}$ concentrations being darker. Within 1 min after the introduction of the $\mathrm{CO}_{2}$ into the top part of the cell, the $\mathrm{pH}$ of the layer of water near the interface began to change and grew thicker over time, as indicated by the darker color (e.g., Fig. 3, Frame 1, 3 min). CSC does not occur in this induction phase. After 3 min, the thickened altered zone became nonuniform, ending the induction time. Following that, many small fingers formed (e.g., Fig. 3, Frame 2, $12 \mathrm{~min}$ ). At this time, only small-scale convection is occurring in the region near the gas-water interface.

As time progressed, the number of fingers advancing downwards decreased, and their width and depth of penetration increased. It is apparent as early as $39 \mathrm{~min}$ into the test, from the nonvertical angles of the fingers that cell-scale convection has initiated (e.g., Fig. 3, Frame $3,39 \mathrm{~min}$ ). In addition, fingers at the top of the cell began to move laterally away from the center. At the left and right boundaries, the $\mathrm{CO}_{2}$-laden fingers flowed downward, but more centrally located fingers were partially slowed or caught in the upward flow at the center.

Once cell-scale convection began, water not laden with $\mathrm{CO}_{2}$ ("fresh") was brought to the surface. There, $\mathrm{CO}_{2}$ dissolved into it, and small fingers formed (e.g., Fig. 3, Frame 5, $132 \mathrm{~min}$ ) and began to grow. New small fingers also formed and grew between established fingers as these were separated by the upward flow resulting from the small-scale convection. Examples of each of these are seen in Fig. 3, Frame 5, 132 min, where a small new finger formed in the top center, and small fingers formed between the larger fingers that become separated by the cell-scale convection (present on both the left and right sides).

Analysis of the images (Fig. 4) shows that there is a decrease in the number of fingers (and increase in the wavelength) over time. Finger lengths were measured from the interface to the tip of the finger. Wavelength was calculated by taking the length of the interface and dividing this by the number of fingers contacting the interface. The widths of individual fingers were not measured. For the period of time when all of the fingers were about the same size, this wavelength would be approximately the same as the wavelength computed from the finger width. Following the induction period, many small fingers formed across the 
gas-water interface and the wavelength was small, after which it increased over time. (The decrease in the number of fingers from the early-time maximum mirrors the wavelength, because the length of the gas-water interface is constant in these tests.) The average length of the fingers in contact with the gas-water interface increased in this period. The standard deviation of finger length is important because it shows that the finger lengths are quite varied. After about $400 \mathrm{~min}$, the rising water in the center with lower $\mathrm{pH}$ began to interfere with finger formation, making it difficult to determine the number of fingers and their length.

\subsection{Test B: $\mathrm{CO}_{2}$ Applied Nonuniformly on the Gas-Water Interface-Vertically Oriented Flat Glass Plates, $0.7 \mathrm{~mm}$ Aperture, $R a_{\mathrm{n}}=1.2 \times 10^{5}$}

In Test $\mathrm{B}$, we introduced the $\mathrm{CO}_{2}$ on the extreme right side of the test cell to examine how the applied shear stress on the gas-water interface affected convective behavior. The density of the water immediately beneath the inlet tube should be affected by the $\mathrm{CO}_{2}$ first, providing a sustained driving force for downward CSC at that location. The $\mathrm{CO}_{2}$ deflected from the gas-water surface will apply a shear stress to the left, counter to the downward flow at the right top corner.

The development of the convective flow system in this test (Fig. 5 ) was similar to that in the Base Case. Numerous small fingers formed very quickly after an induction time that lasted less than $8 \mathrm{~min}$. The finger wavelength increased early on, remained relatively constant for about $2 \mathrm{~h}$, and then increased until it became difficult to distinguish new finger formation because upward flowing water already had been impacted by $\mathrm{CO}_{2}$. The major difference between this test and the Base Case is that there was an imbalance in the size of the circulating regions, with the left circulating cell now occupying about $70 \%$ of the test cell, and the right circulation occupying $30 \%$ of the test cell. This indicates that the $\mathrm{CO}_{2}$-induced shear at the gas-water interface impacted the cell formation, adding driving force to the left side and resistance to the right. Many more fingers formed on the left, and they become much larger than those on the right. Over time, however the cells tended to equalize in size, and toward the end of the experiment, it was very difficult to detect the border separating the sides.

\subsection{Test C: Reduced Gravity Case-Flat Glass Plates Oriented $60^{\circ}$ from Vertical, $0.7 \mathrm{~mm}$ Aperture, $R a_{\mathrm{n}}=6 \times 10^{4}$}

In Test $\mathrm{C}$, we reduced the strength of gravity in the plane of the cell by a factor of 2 by orienting the cell at $60^{\circ}$ from the vertical. In order to do this, we oriented the light table at $30^{\circ}$ from horizontal and rested the Hele-Shaw cell used in the previous two tests on spacers on the light table. The spacers were used to allow airflow on all sides to minimize thermal gradients. $\mathrm{CO}_{2}$ was introduced at the center near the gas-water interface.

In the test setup, fluid was introduced into the cell in two aliquots. In spite of careful rinsing of the container prior to use, there was a slight $\mathrm{pH}$ difference between the two portions. Thus, two regions having slightly different initial colors were distributed in the test cell (enhanced in Fig. 6a). In the initial color distribution, the lower left "boot-shaped" region was slightly more yellowish in color (slightly more acidic) than the rest of the fluid in the cell. This slight difference provides a convenient tracer because when subtracting the initial condition from later images, redistribution of the fluids can be detected. In Fig. 6b, invasion of the less acidic (bluish) region into the more yellowish region results in lighter shades of gray, whereas the invasion of more acidic (yellowish) colored fluid results in a darker region in the figure (See Fig. 6b and caption). 


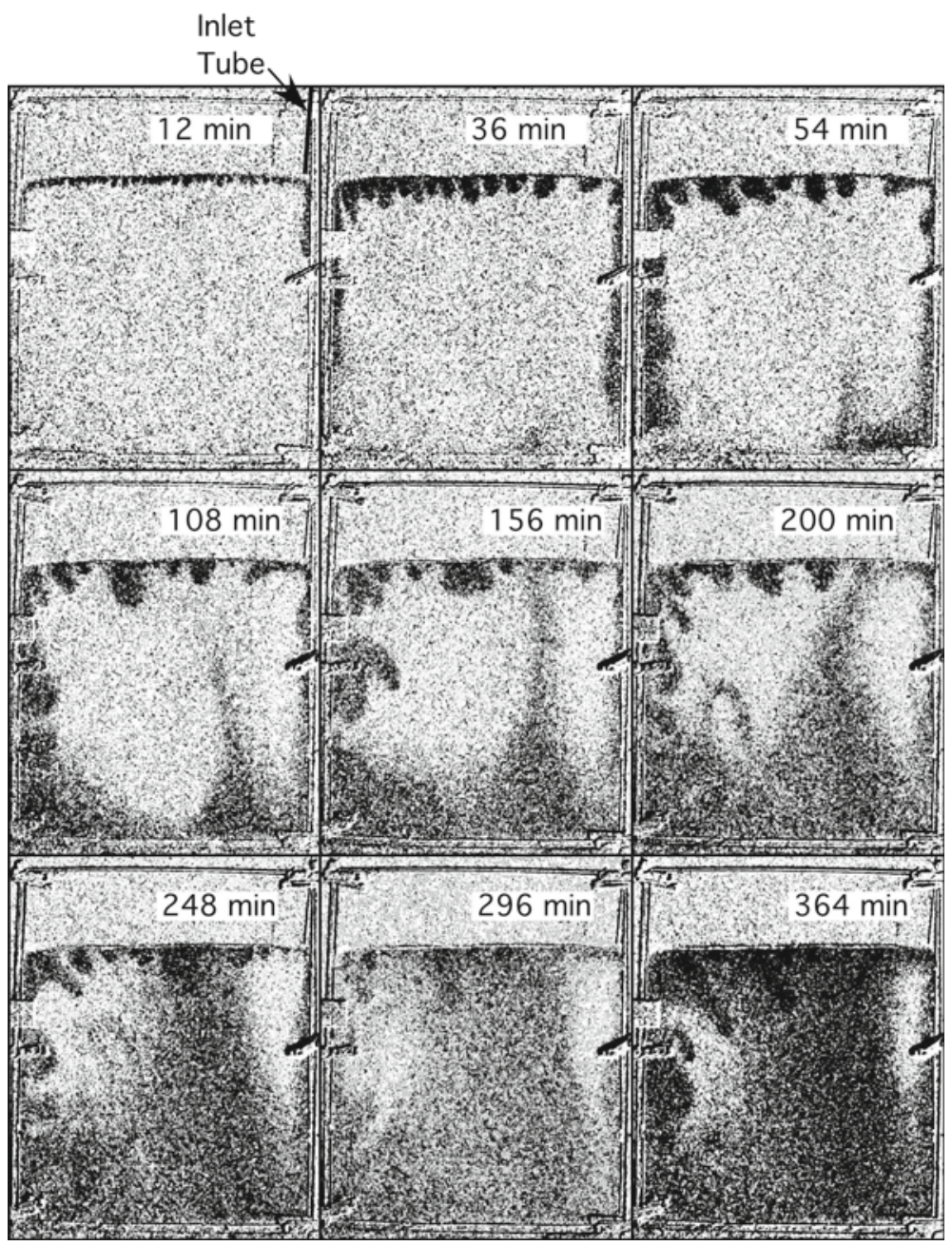

Fig. 5 Same as Base Case but $\mathrm{CO}_{2}$ introduced at steep slope impinging on interface at the right side

As in the Base Case, a small layer of lower $\mathrm{pH}$ fluid initially forms near the gas-water interface (Fig. 6b, Frame 1, $4 \mathrm{~min}$ ). Within $8 \mathrm{~min}$, this layer becomes nonuniform and within $12 \mathrm{~min}$, small fingers begin to form indicating the end of the induction period (fingers were beginning to form at about $3 \mathrm{~min}$ in the Base Case). As in the Base Case, over time these fingers become longer and wider, and more space developed between them. As early as 8 min into the experiment, indications of cell-scale convection are visible, as differences can be discerned along the original darker/lighter-colored fluid boundary (e.g., Fig. 6b, Frame 2, $16 \mathrm{~min}$ ). This early cell-scale circulation is slightly off-center, with upflow being more predominant on the right at about $30 \mathrm{~min}$ into the test. By $1 \mathrm{~h}$, however, the upflow is centered in the test cell. As in the Base Case, "fresh" water is brought to the surface either by large or small-scale convection where new small fingers begin to form, which then grow vertically and flow laterally as governed by both the cell-scale convection and the smaller finger-scale convection. The convection pattern established after $144 \mathrm{~min}$ persists for the duration of the experiment (14 h). 
Fig. 6 Reduced gravity case (a) initial condition with two regions indicated, and (b) difference images. Ellipse in Frame 2 (16 min) shows an example of where the more blue fluid is replacing the yellower fluid, and the rectangle shows an example of where the yellower fluid is replacing blue fluid

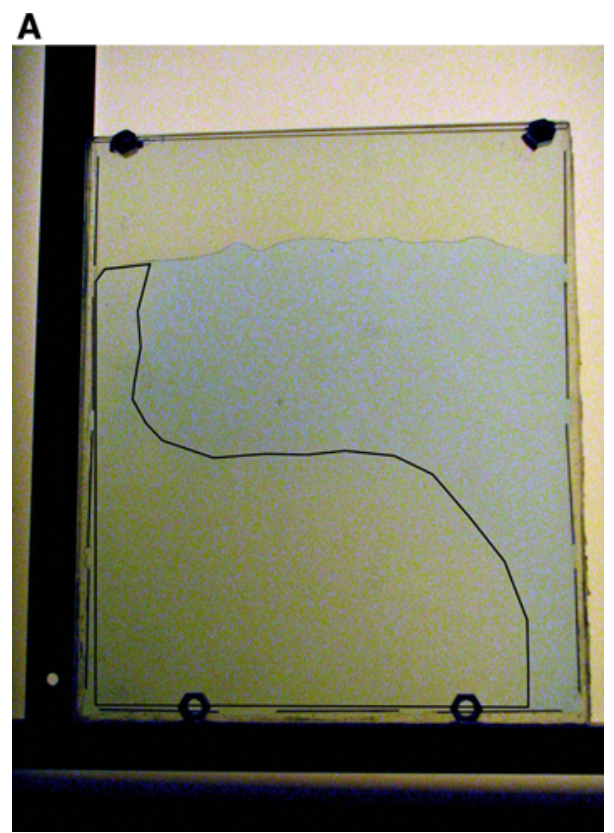

\subsection{Test D: Heterogeneous Case-Textured Sandblasted Vertical Glass Plates, $0.9 \mathrm{~mm}$} Aperture, $R a_{\mathrm{n}} \approx 2.0 \times 10^{5}$

Two $21.6 \times 33 \mathrm{~cm}$ textured glass (P516) plates were sandblasted and placed with textured sandblasted sides toward each other, separated by $0.9 \mathrm{~mm}$ graphite shims. The sandblasting was performed by hand both horizontally and vertically, resulting in a heterogeneous "Cartesian" imprint on the glass. Two scales of roughness are present in the glass: the $\sim 2 \mathrm{~cm}$ scale from the passing of the sandblasting gun, removing tens of microns of glass; and the $\sim 5$ $\mathrm{mm}$ scale, with the texture of the glass having a peak-to-valley height of several hundred microns. The resulting nonuniform aperture size is estimated to be approximately $0.95 \pm 0.1$ $\mathrm{mm}$. Images were collected for $600 \mathrm{~min}$ in this test-every minute for the first $100 \mathrm{~min}$, and every 5 min thereafter.

Figure 7 shows the development of the CSC in this test. As in the previous tests, small fingers formed rapidly, but in this test the induction period was less than $1 \mathrm{~min}$. The fingers were clearly influenced by the heterogeneous structure of the cell, since some fingers tended to stay in the same location-for example, the large, thick finger to the left of center (Fig. 7, left arrow in Frame 8,77 min) —or form at specific, somewhat fixed locations, such as the low point of the gas-water interface just to the right of center (right arrow in Fig. 7, Frame 8, $77 \mathrm{~min}$ ), before being swept away by the cell-scale convection.

The CSC flow in this test was the most varied as well. Finger splitting occurred more in this test than others. This bifurcation was caused by upward moving fingers of fresh water dividing the downward moving $\mathrm{CO}_{2}$-laden finger. In certain central locations, flow was proceeding downwards 100 min into the test, however those downward flows were later overtaken by the large-scale upward convection after about $150 \mathrm{~min}$. Fingers continued to form and CSC occurred over the entire duration of the imaging. 


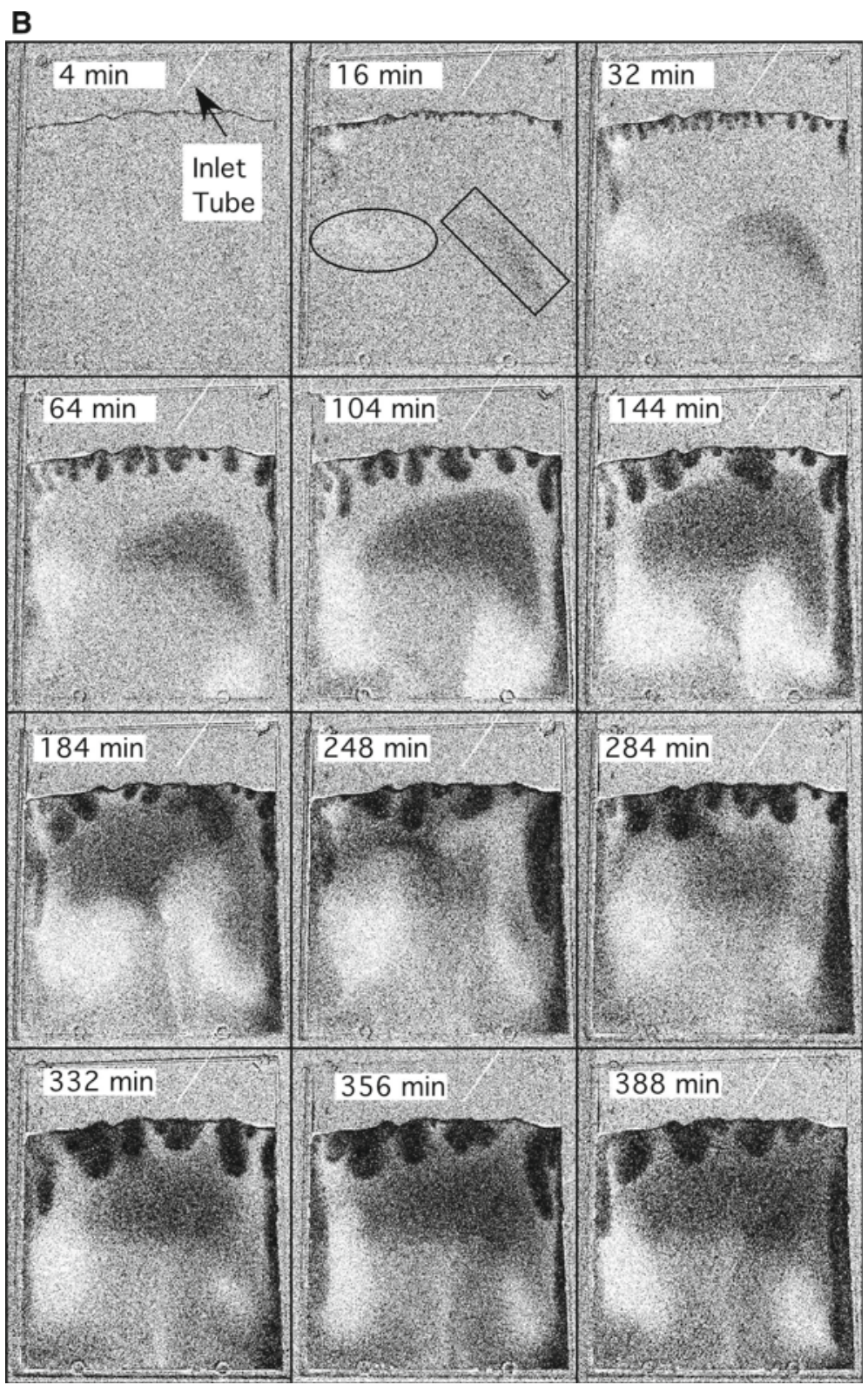

Fig. 6 continued

\section{Numerical Simulation}

Simulations of the Base Case experimental system were performed using TOUGH2/ECO2N (Pruess and Spycher 2007) and the parameters listed in Table 1. Because of the spatial scales of the processes that occur in the absorption of the $\mathrm{CO}_{2}$ including dissolution at the interface, diffusion near the gas-water interface, and convection at multiple scales, the dimensions of 


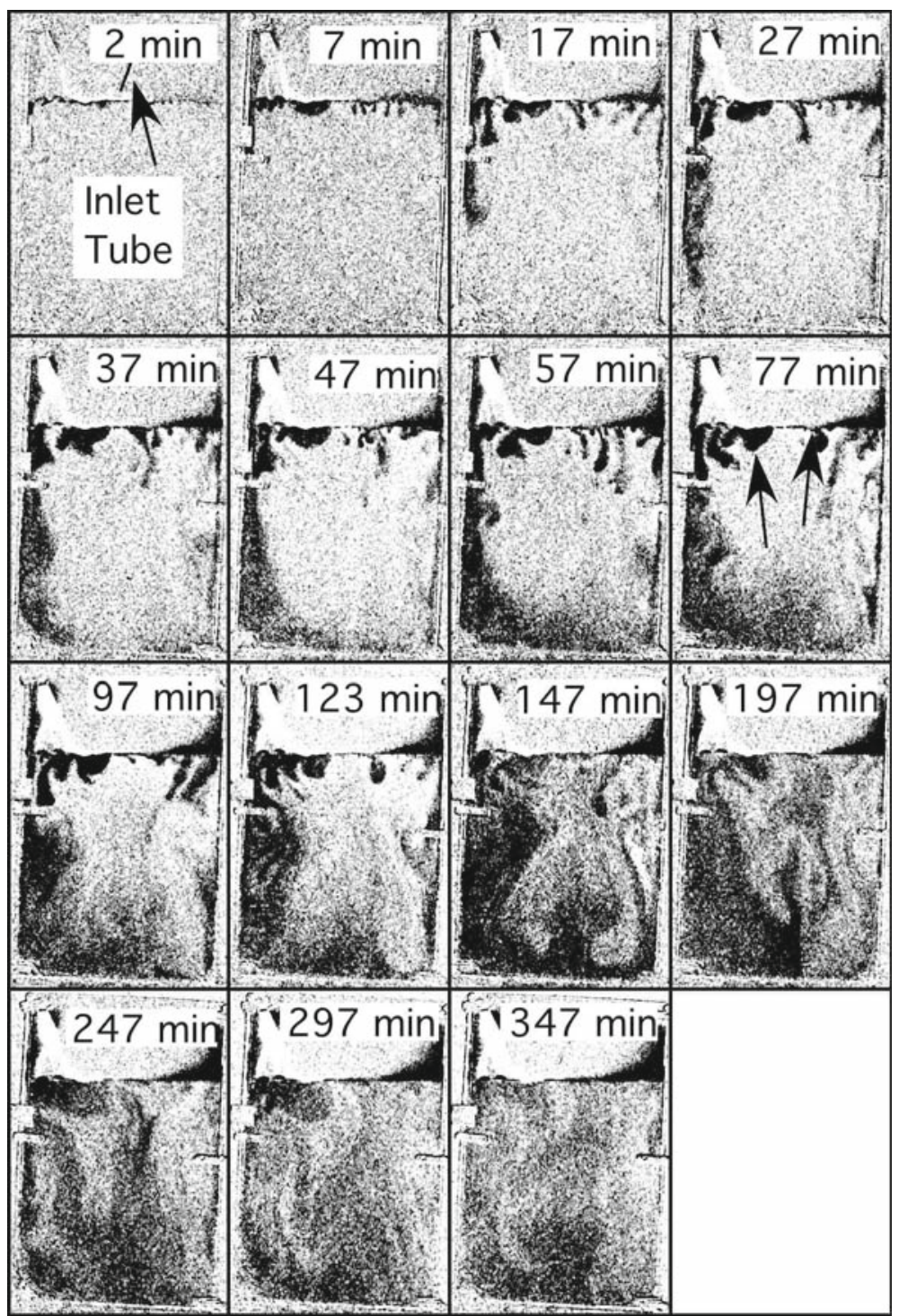

Fig. 7 Difference images for the heterogeneous case

the grid blocks varied in the vertical direction starting from $10^{-5} \mathrm{~m}$ at the gas-water interface, 20 rows having a vertical dimension of $10^{-3} \mathrm{~m}$, and the rest of the domain was filled with blocks having a vertical dimension of $2.2 \times 10^{-3} \mathrm{~m}$. The horizontal grid spacing was uniform at $2.4 \times 10^{-3} \mathrm{~m}$. Permeability was assigned based on the parallel-plate aperture $\mathrm{b}=7 \times 10^{-3}$ $\mathrm{m}$ as $\mathrm{k}=\mathrm{b}^{2} / 12=4.08 \times 10^{-8} \mathrm{~m}^{2}$.

Results of the simulations are presented together with images from the experiment at two times in Fig. 8. Several similarities and differences between the numerical and experimental systems are apparent. First, the cell-scale convection does not occur in the numerical simulation. In the experimental system, the cell-scale convection is readily visible as the angle of 
Table 1 Parameters used for Hele-Shaw cell simulations

\begin{tabular}{ll}
\hline Fluid properties & $T=22^{\circ} \mathrm{C}$ \\
Temperature & $P=1.013 \mathrm{bar}$ \\
Pressure & $\begin{array}{l}X_{\mathrm{S}}=0 \\
\text { Salinity }\end{array}$ \\
$\begin{array}{l}\text { Dissolved } \mathrm{CO}_{2} \text { concentration } \\
\text { Viscosity }\end{array}$ & $\begin{array}{l}\mu=0.954766 \times 10^{-3} \mathrm{~Pa}-\mathrm{s} \\
\rho=997.889 \mathrm{~kg} / \mathrm{m}^{3}\end{array}$ \\
$\begin{array}{l}\text { Water density } \\
\text { Dissolved } \mathrm{CO}_{2} \text { mass fraction at the }\end{array}$ & $X_{0}=1.53377 \times 10^{-3}$ \\
$\begin{array}{l}\text { top boundary } \\
\text { Density increase of aqueous phase } \\
\text { from } \mathrm{CO}_{2} \text { dissolution }\end{array}$ & $\Delta \rho=0.287 \mathrm{~kg} / \mathrm{m}^{3}$ \\
$\begin{array}{l}\text { Diffusivity } \\
\text { Formation properties }\end{array}$ & $D=10^{-9} \mathrm{~m}^{2} / \mathrm{s}$ \\
$\begin{array}{l}\text { Porosity } \\
\text { Permeability }\end{array}$ & $\phi=1.0$ \\
$\begin{array}{l}\text { Model domain } \\
\text { Height } \\
\text { width }\end{array}$ & $k=4.08 \times 10^{-8} \mathrm{~m}^{2}$ \\
& $H=0.24 \mathrm{~m}$ \\
& $W=0.24 \mathrm{~m}$
\end{tabular}

the fingers changes with distance from the center, long fingers accumulate along the sides, and the dark gray color throughout the bottom in the 324-min image indicating the presence of $\mathrm{CO}_{2}$-laden water at the bottom of the cell (Fig. 3 shows the convection development). Some degree of cell-scale convection was observed in all the experimental systems, even those not presented here.

The fingers in the experimental system are broader than those in the numerical system and there are fewer of them. This may be because the numerical system requires finite grid dimensions, whereas the experimental system is a continuous system. The gridding is clearly fine enough to produce fingers of the scale observed experimentally. Additionally, in the experimental system, there are deviations in the elevation of the gas-water interface providing instability points. These occur because of wetting inhomogeneities on the glass. None of these imperfections are present in the numerical system. Another difference is the variability in finger length. At both times, but particularly the later time, the finger length appears more uniform in the numerical model results. A number of new short fingers are observed in the experimental system, whereas few new fingers appear in the numerical system. In spite of these differences, there are similarities between the simulations and experimental results. Fingers form on the same time scale. The mean finger lengths and frequencies are about the same for the corresponding times.

\section{Discussion}

The rapid initiation of cell-scale convection in the experiments was not expected nor predicted using the numerical models. Small fingers forming at a large distance from the bottom of the cell were expected to induce local convection on the scale of the finger lengths. The presence of cell-scale convection in the laboratory experiments and its absence in numerical simulations may be due to a thermal convection from constant illumination, or possibly the free-surface boundary condition in the experiments. Both of these mechanisms could explain why downflow did not generally occur in the cell center but typically at the sides, and upflow occurred toward the center. A test was performed to examine thermal convection by emplacing two concentrations of the bromocresol green solution in the Hele-Shaw cell 

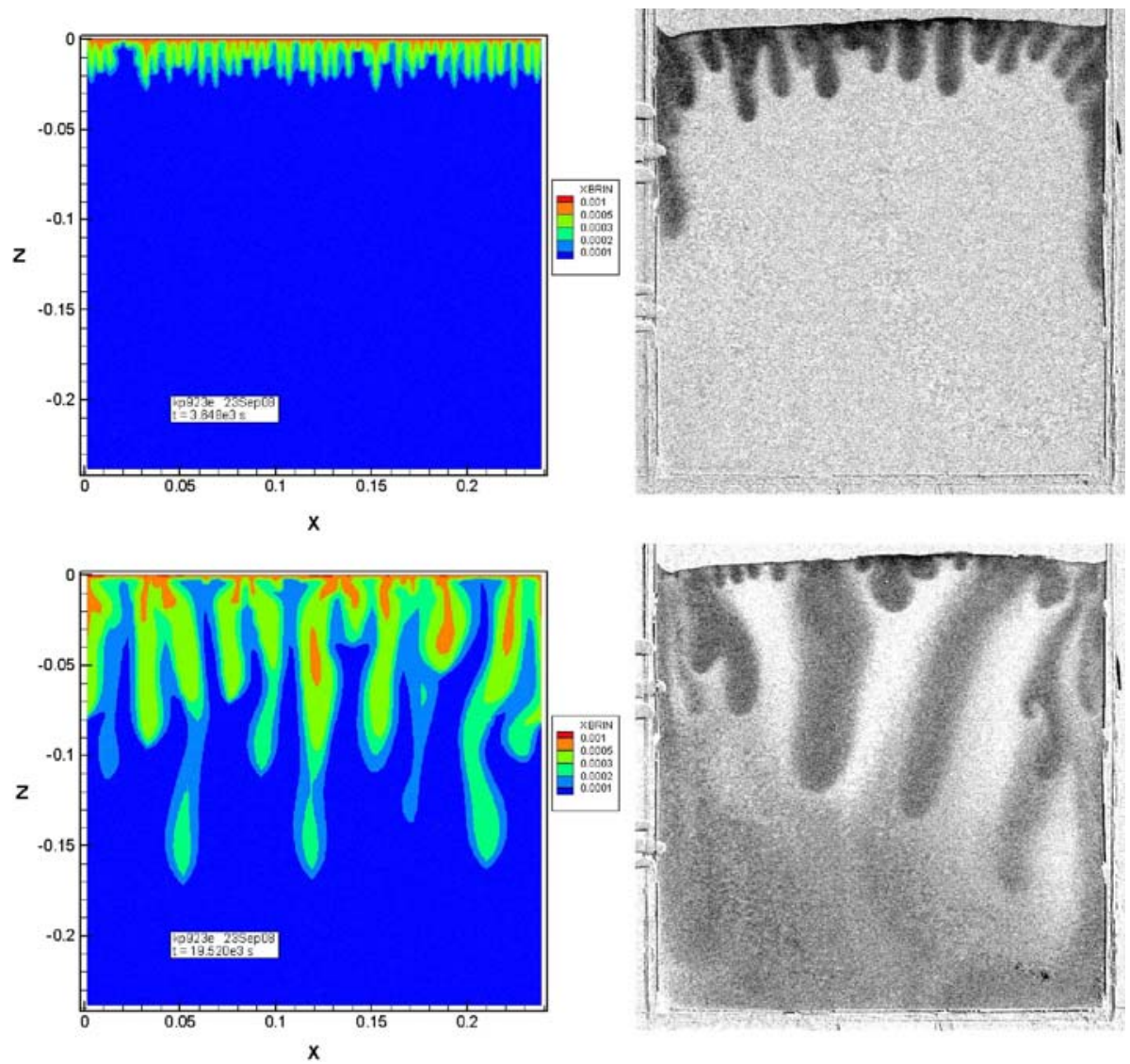

Fig. 8 Simulated and experimentally observed fingering patterns for the Base Case at 60 min (top) and 324 $\min ($ bottom $)$

$\left(\mathrm{CO}_{2}\right.$ was not introduced). The bromocresol green concentrations were similar so as to not induce CSC by themselves, however, just different enough that with image processing fluid motion could be detected. The cell was monitored without the backlight for an hour, and then illuminated for several hours while the backlight was on. Cell-scale convection was observed while illuminated, with the time of circulation on the order of six or so hours compared to $\sim 1$ $\mathrm{h}$ or so for the tests with CSC. This mild thermal convection-presumably caused by a very small temperature difference from the center of the cell to the edge-could have provided an instability that enhanced the CSC. The CSC also enhanced this thermal convection speeding up the circulation. The free boundary condition has not yet been investigated.

In carbon sequestration, the importance of CSC is that it accelerates the uptake of $\mathrm{CO}_{2}$ by enhanced aqueous dissolution compared to diffusion. We computed an approximate measure of $\mathrm{CO}_{2}$ uptake in our test cells by comparing the average change in light intensity with the change in light intensity for obviously $\mathrm{CO}_{2}$-impacted zones (new fingers). From this, we calculated the "Area Affected" as the relative area of the changed intensity to the cell area (e.g., darkened area-area containing depressed $\mathrm{pH}$ water-to the total area occupied by water in Figs. 2, 3, 5, 6, 7). For each image, this was computed by taking the red and green 8-bit color channels and adding a nominal value (e.g., 20 or 50) exceeding the overall variability 

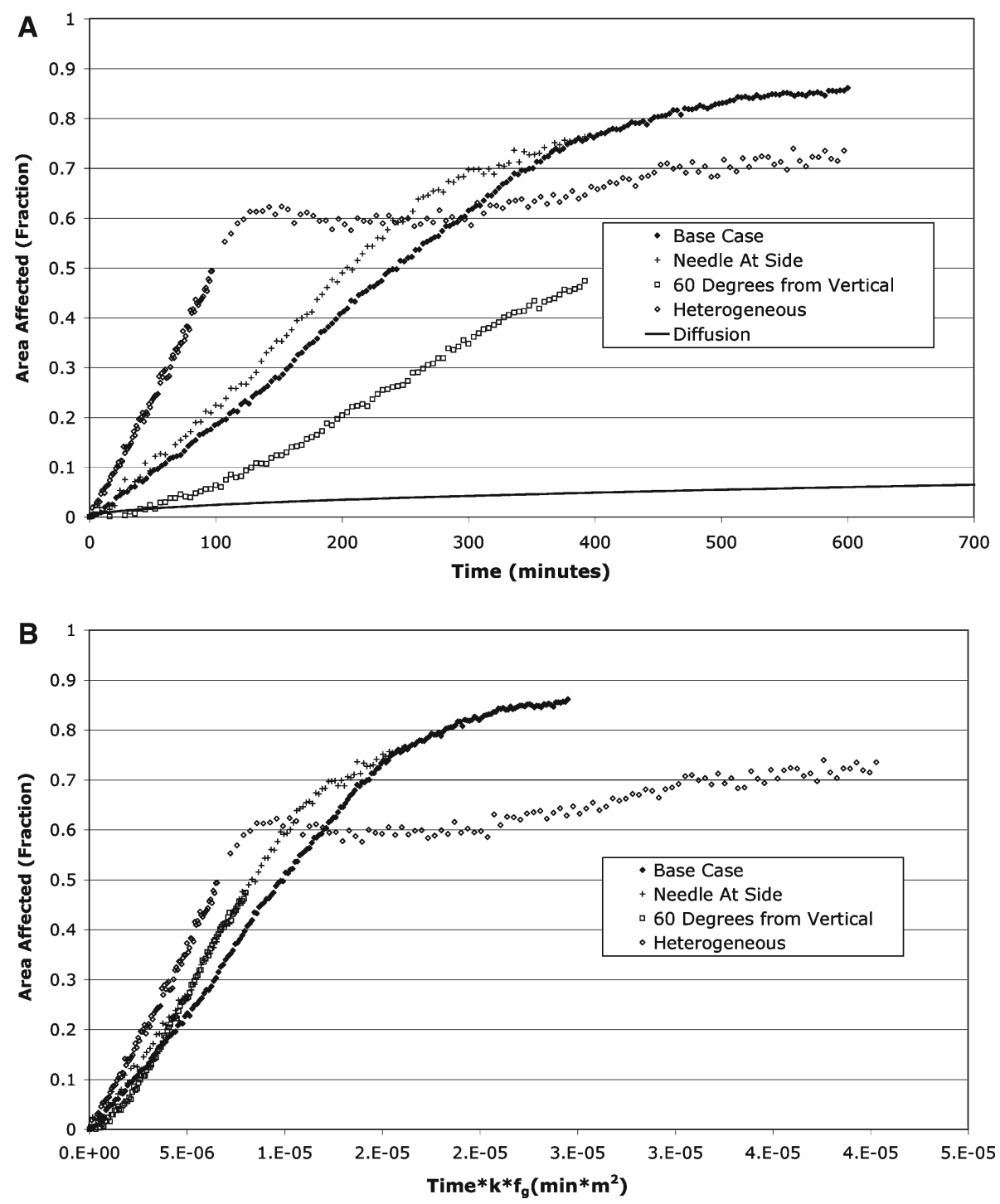

Fig. 9 Raw (a) and scaled (b) fraction of the area (volume) affected by $\mathrm{CO}_{2}$ for the four tests

of a control region (on the order of five) of the images such that image differencing would not result in clipping of the values (in 8-bit subtraction, $20-30=0$ ). The corresponding channel of the initial image was then subtracted resulting in the difference plus the nominal value. The red and green difference images were then added, doubling the nominal value added. From these images, the mean intensity of both the water-filled and control areas were computed. In order to determine the affected area, the intensity of the internal region of a finger was hand selected in at least ten images over the duration of the test, and for each image, the control value was subtracted from the finger mean value (subtracting the nominal value out). The resulting values were then averaged. The "Affected Area" was then computed 
by taking the ratio of the difference in mean intensity between the water-filled and controlled regions (in taking the difference, the nominal value was subtracted out), with the average difference between the finger intensity and the control. Figure 9a shows this computed $\mathrm{CO}_{2}$ uptake as "Area Affected," and the computed $\mathrm{CO}_{2}$ uptake for the diffusion-only case. In spite of the noise and uncertainty in the analysis (we assume that the affected area is saturated with $\mathrm{CO}_{2}$ ), it appears that in these tests which all had obvious $\mathrm{CSC}, \mathrm{CO}_{2}$ was absorbed much more rapidly than the computed diffusion-only case. This would be expected for such high $R a_{\mathrm{n}}$ systems. We have not yet studied low $R a_{\mathrm{n}}$ systems for comparison.

When the time axis is scaled using the permeability and gravitational factor (the variables we varied in the $R a_{\mathrm{n}}$ ), the initial portions of the curves in Fig. 9a nearly collapse into a single curve (Fig. 9b). Affected areas from later in the tests also tend to fall below the initial scaled trend, which is expected because the rate of $\mathrm{CO}_{2}$ uptake will decrease when $\mathrm{CO}_{2}$-laden water is recycled to the interface.

We have established a visualization technique for investigating CSC at the bench top scale that will be further refined in the future and made more quantitative, to serve as a means for testing the predictions of numerical models. We plan to test many CSC phenomena using a variety of cells. A better description of the induction phase is needed. Although we have several observations of this phase, our data collection frequency was not adequate to quantify the duration of the induction phase under a variety of conditions. In ongoing experiments, we will more closely study the early stages of CSC in our cells by slowing system evolution, through (1) further inclining our cells and (2) using brine instead of pure water. The early period is important because it provides a better analogy to larger-scale behavior in the field where the effects of boundaries would be detected only after a long time.

\section{Conclusions}

CSC has been shown to occur in numerical simulations, quantitative studies, and visualization experiments described here. Visualizations show that during the initial induction phase, $\mathrm{CO}_{2}$ dissolves and diffuses into the water at the $\mathrm{CO}_{2}$-water interface. Following that, many small fingers begin to develop and this alters local and larger-scale flow. As the small fingers grow, their size and location are impacted by the flow field heterogeneity, flow induced by the fingering, and the larger-scale flow. Processes were observed at multiple scales in these simple tests. One result of CSC is a significant enhancement in the uptake rate of $\mathrm{CO}_{2}$ into the system. Numerical modeling performed here showed similarities to the experiments in terms of finger formation and the formation time scale, while showing differences in the variability of finger length and cell-scale convection. The cell-scale convection may be induced by a mild thermal gradient from the cell illumination or a free upper boundary. Additional testing is needed to understand this behavior. Upscaling and numerical simulations are needed to determine the importance of this CSC enhancement at reservoir scale. Only a few sets of conditions have been investigated so far. Many more conditions need to be tested and evaluated to provide a robust data set for conceptual model refinement and numerical simulator comparison.

Acknowledgments We are grateful to Carrie Tse who helped in the setup and analysis of the experiments, and to Jil Geller, Dan Hawkes, and two anonymous reviewers for helpful comments in reviewing this manuscript. This study was supported by the Director, Office of Science, Office of Basic Energy Sciences, Division of Chemical Sciences, Geosciences, and Biosciences, of the U.S. Department of Energy under Contract No. DE-AC02-05CH11231. 
Open Access This article is distributed under the terms of the Creative Commons Attribution Noncommercial License which permits any noncommercial use, distribution, and reproduction in any medium, provided the original author(s) and source are credited.

\section{References}

Audigane, P., Gaus, I., Czernichowski-Lauriol, I., Pruess, K., Xu, T.: Two-dimensional reactive transport modeling of $\mathrm{CO}_{2}$ injection in a saline aquifer at the Sleipner site North Sea. Am. J. Sci. 307, 9741008 (September 2007). doi:10.2475/07.2007.02

Ennis-King, J., Paterson, L.: Rate of dissolution due to convective mixing in the underground storage of carbon dioxide. In: Gale, J., Kaya, Y. (eds.) Greenhouse Gas Control Technologies, vol. 1, pp. 507-510, Elsevier, Amsterdam (2003a)

Ennis-King, J., Paterson, L.: Role of convective mixing in the long-term storage of carbon dioxide in deep saline formations. Paper SPE-84344 presented at Society of Petroleum Engineers Annual Fall Technical Conference and Exhibition, Denver, CO, October 2003b

Ennis-King, J., Preston, I., Paterson, L.: Onset of convection in anisotropic porous media subject to a rapid change in boundary conditions. Phys. Fluids 17, 084107 (2005). doi:10.1063/1.2033911

Ennis-King, J., Green, C., Pruess, K.: Effect of vertical heterogeneity on long-term migration of $\mathrm{CO}_{2}$ in saline formations. Presented at 9th International Conference on Greenhouse Gas Control Technologies, Washington DC, November 2008

Farajzadeh, R., Salimi, H., Zitha, P.L.J., Bruining, H.: Numerical simulation of density-driven natural convection in porous media with application for $\mathrm{CO}_{2}$ injection projects. Int. J. Heat Mass Transf. 50, 5054-5064 (2007)

Garcia, J.: Density of Aqueous Solutions of $\mathrm{CO}_{2}$. Lawrence Berkeley National Laboratory Report LBNL49023, Berkeley, CA (2001)

Garg, S.K., Kassoy, D.R: Convective heat and mass transfer in hydrothermal systems. In: Rybach, L., Muffler, L.J.P. Geothermal Systems: Principles and Case Histories, Wiley, Chichester (1981)

Hesse, M.A., Tchelepi, H.A., Orr, Jr. F.M.: Natural convection during aquifer $\mathrm{CO}_{2}$ storage. Presented at 8th International Conference on Greenhouse Gas Control Technologies, Trondheim, Norway, June 2006

IPCC: IPCC special report on carbon dioxide capture and storage. In: Metz, B., Davidson, O., de Coninck, H.C., Loos, M., Meyer, L.A. (eds.) Prepared by Working Group III of the Intergovernmental Panel on Climate Change Cambridge University Press, Cambridge and New York, NY, 442 pp. (2005)

Lindeberg, E., Wessel-Berg, D.: Vertical convection in an aquifer column under a gas cap of $\mathrm{CO}_{2}$. Energy Convers. Manag. 38(Suppl), S229-S234 (1997)

Lindeberg, E., Bergmo, P.: The long-term fate of $\mathrm{CO}_{2}$ injected into an aquifer. In: Gale, J., Kaya, Y. (eds.) Greenhouse Gas Control Technologies, pp. 489-494. Elsevier Science Ltd, Amsterdam, The Netherlands (2003)

Pruess, K., Spycher, N.: ECO2N-A fluid property module for the TOUGH2 code for studies of $\mathrm{CO}_{2}$ storage in saline aquifers. Energy Convers. Manag. 48(6), 1761-1767 (2007). doi:10.1016/j.enconman.2007.01. 016

Pruess, K., Zhang, K.: Numerical Modeling Studies of the Dissolution-Diffusion-Convection Process During $\mathrm{CO}_{2}$ Storage in Saline Aquifers. Lawrence Berkeley Laboratory Report LBNL-1243E, Berkeley CA (2008)

Rasband, W.S.: ImageJ. U.S. National Institutes of Health, Bethesda, Maryland, USA. http://rsb.info.nih.gov/ $\mathrm{ij} /(1997-2008)$

Riaz, A., Hesse, M., Tchelepi, H.A., Orr, Jr. F.M.: Onset of convection in a gravitationally unstable diffusive boundary layer in porous media. J. Fluid Mech. 548, 87-111 (2006)

Weir G.J., White S.P., Kissling W.M.: Reservoir storage and containment of greenhouse gases. In: Pruess K. (ed.) Proceedings of the TOUGH Workshop '95, pp. 233-238. Lawrence Berkeley National Laboratory Report LBL-37200, Berkeley, CA (1995)

Weir, G.J., White, S.P., Kissling, W.M.: Reservoir storage and containment of greenhouse gases. Transp. Porous Media 23, 37-60 (1996)

Xu, X., Chen, S., Zhang, D.: Convective stability analysis of the long-term storage of carbon dioxide in deep saline aquifers. Adv. Wat. Resour. 29, 397-407 (2006)

Yang, C., Gu, Y: Accelerated mass transfer of $\mathrm{CO}_{2}$ in reservoir brine due to density-driven natural convection at high pressures and elevated temperatures. Ind. Eng. Chem. Res. 45, 2430-2436 (2006) 